\title{
Current findings for recurring mutations in acute myeloid leukemia
}

\author{
Shinichiro Takahashi
}

\begin{abstract}
The development of acute myeloid leukemia (AML) is a multistep process that requires at least two genetic abnormalities for the development of the disease. The identification of genetic mutations in AML has greatly advanced our understanding of leukemogenesis. Recently, the use of novel technologies, such as massively parallel DNA sequencing or high-resolution single-nucleotide polymorphism arrays, has allowed the identification of several novel recurrent gene mutations in AML. The aim of this review is to summarize the current findings for the identification of these gene mutations (Dnmt, TET2, IDH1/2, NPM1, ASXL1, etc.), most of which are frequently found in cytogenetically normal AML. The cooperative interactions of these molecular aberrations and their interactions with class I/II mutations are presented. The prognostic and predictive significances of these aberrations are also reviewed.
\end{abstract}

Keywords: gene mutations, acute myeloid leukemia, cooperative interactions

\section{Introduction}

The identification of mutations in certain genes, such as the fms-related tyrosine kinase 3 (FLT3), CCAAT/ enhancer binding protein alfa $(C / E B P \alpha)$, runt-related transcription factor 1 (RUNX1), myeloid-lymphoid or mixed lineage leukemia (MLL), Wilms tumor (WT1) and nucleophosmin (NPM) 1 genes, in acute myeloid leukemia (AML) has significantly improved our understanding of leukemogenesis [1-4]. This is particularly the case for patients with normal cytogenetics, who comprise the largest subgroup (approximately 45\%) of AML patients [5-7]. In fact, assessments of the presence of internal tandem duplications in the FLT3 receptor gene (FLT3-ITD) [8] and mutations in the NPM1 gene [4] are currently routine practices in guiding therapeutic decisions in AML patients with a normal karyotype [9]. Recent studies have revealed prevalent mutations, such as DNA methyltransferase (Dnmt) 3a mutations [10], ten-eleven-translocation oncogene family member 2 (TET2) [11] mutations and isocitrate dehydrogenase (IDH) 1 gene mutations [3], using novel technologies like high-throughput massively parallel DNA sequencing

Correspondence: shin@kitasato-u.ac.jp

Division of Molecular Hematology, Kitasato University Graduate School of Medical Sciences and Division of Hematology, Kitasato University School of Allied Health Sciences, 1-15-1 Kitasato, Minami-ku, Sagamihara 252-0373, Japan

\section{C) Biomed Central}

[12]. Indeed, AML is increasingly subclassified as a unique entity in the 2008 revision of the World Health Organization classification of myeloid neoplasms and acute leukemia [13], based on specific recurring genetic abnormalities that can predict the prognosis and response to therapy [7].

AML development is considered to be a multistep process that requires the collaboration of at least two classes of mutations to obtain full-blown leukemia. Almost a decade ago, Gilliland and Griffin [14] presented a paradigm model for this process, designated the "two-hit model". This model comprises class I mutations that activate signal transduction pathways and confer a proliferation advantage on hematopoietic cells, and class II mutations that affect transcription factors and primarily serve to impair hematopoietic differentiation $[15,16]$. Mutations leading to activation of the receptor tyrosine kinase (RTK) FLT3, c-kit (KIT) and Ras signaling pathway are considered to be class I mutations. Recurring chromosomal aberrations such as $\mathrm{t}(8$; $21)$, inv(16) and $t(15 ; 17)$, which generate fusion transcripts of RUNX1/ETO, CBF $\beta / M Y H 11$ and PML/RAR $\alpha$, respectively, fall into class II mutations. Not only chromosomal abnormalities but also mutations of the transcription factors RUNX1, C/EBP $\alpha$ and MLL are classified into this group. These "classical" class I and 
class II mutations are presented in Figure 1. However, most of the newly identified genetic alterations, such as those in Dnmt, TET2, IDH1, IDH2, NPM1, ASXL1, which are addressed mainly in this review, have not been classified because the consequences of these mutations have not been identified. In this review, each of these "unclassified mutations" is detailed individually. The author summarizes the current findings of these novel gene mutations, most of which are frequently found in cytogenetically normal AML (CN-AML). The

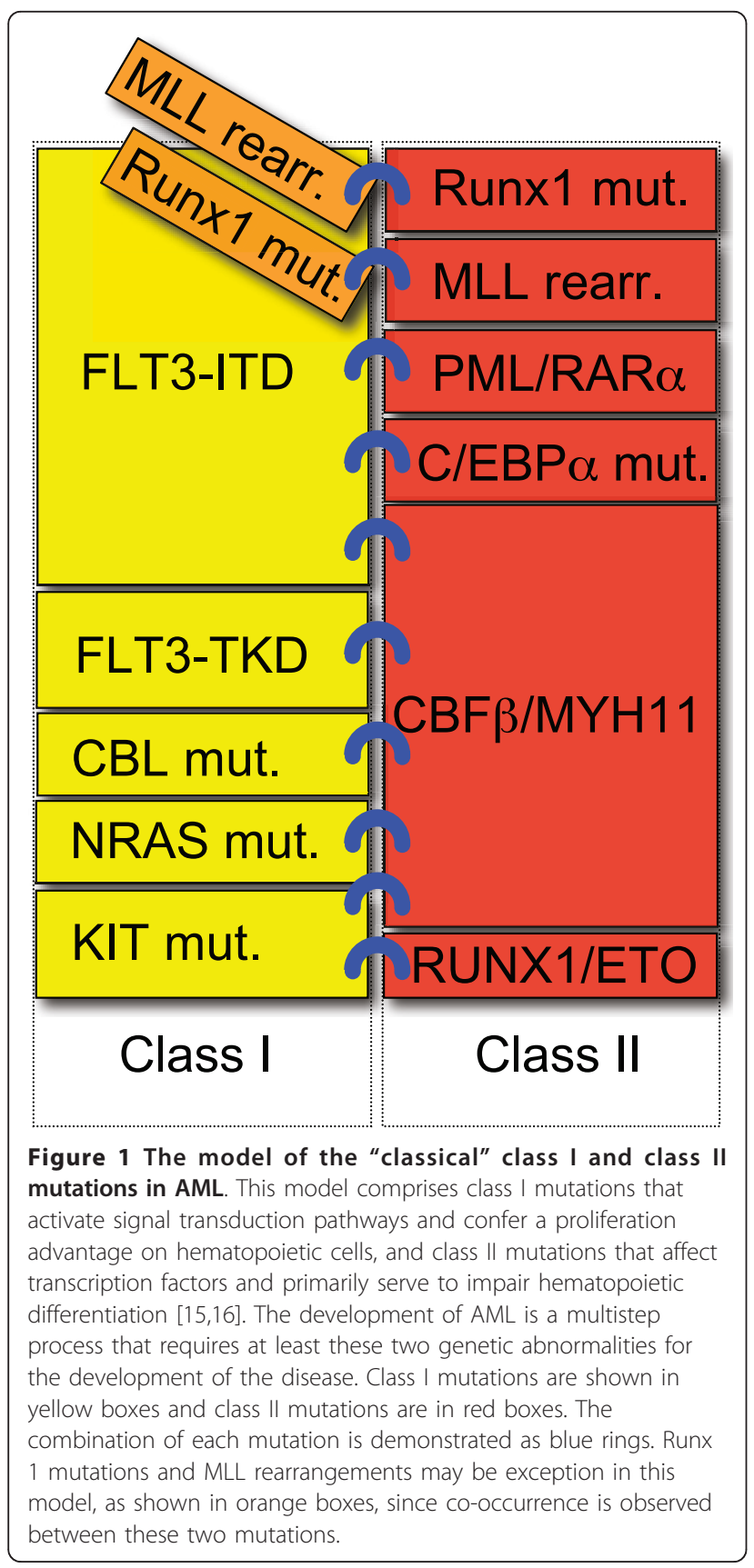

cooperative interactions of the molecular aberrations are also presented.

\section{Dnmt mutations}

Dnmts are enzymes that catalyze the addition of a methyl group to the cytosine residue of $\mathrm{CpG}$ dinucleotides. Aberrant $\mathrm{CpG}$ island methylation has long been hypothesized to contribute to the pathogenesis of cancer [17]. Recently, using massively parallel DNA sequencing [12], Ley et al. [10] identified a somatic mutation in Dnmt3a by sequencing 116.4 billion base pairs of the sequence with $99.6 \%$ diploid coverage of the genome of cells from an AML patient with a normal karyotype. Further analyses revealed the presence of Dnmt3a mutations in 62 of 281 AML patients (22.1\%). These mutations were highly enriched in a group of patients with an intermediate-risk cytogenetic profile, as well as mutations in FLT3 (either ITD or tyrosine kinase domain [TKD] mutations), NPM1 and IDH1. The median overall survival (OS) among patients with Dnmt3a mutations was significantly shorter than that among patients without such mutations (12.3 vs. 41.1 months, $\mathrm{p}<0.001$ ) [10] (Table 1). Walter et al. [18] also described relatively frequent mutations in myelodysplastic syndrome (MDS). They carried out sequencing for 150 patients with MDS, and identified 13 heterozygous mutations with predicted translational consequences in 12 patients (8.0\%). Yan et al. [19] discovered Dnmt3a mutations in 23 of 112 cases (20.5\%) with the M5 subtype of AML. They revealed that, although Dnmt3a mutations do not dramatically alter global DNA methylation levels in AML genomes [10], there were alterations of specific gene DNA methylation patterns and/or gene expression profiles, such as HOXB genes, in samples with Dnmt3a mutations compared with those without such changes [19]. Consistent with these observations, the Dnmt3a mutations, which frequently occurred in arginine (R) 882, caused reduced enzymatic activity in vitro [19].

\section{TET2 mutations}

In 2009, Delhommeau et al. [11] conducted high-resolution single-nucleotide polymorphism and comparative genomic hybridization arrays to identify a candidate tumor-suppressor gene common to patients with MDS, myeloproliferative disorders and AML. They identified inactivating mutations of the TET2 gene in about $15 \%$ of patients with various myeloid malignancies, such as MDS (19\%), myeloproliferative disorders (12\%), secondary AML (24\%) and chronic myelomonocytic leukemia (CMML) (22\%) [11]. TET2 can convert 5-methylcytosine $(5-\mathrm{mC})$ to 5 -hydroxymethylcytosine $(5-\mathrm{hmC})$ [20], which to be an intermediate in DNA demethylation. Bone marrow samples from patients with TET2 mutations displayed uniformly low levels of $5-\mathrm{hmC}$ in 
Table 1 Clinical features of gene mutations in AML (unclassified mutations)

\begin{tabular}{|c|c|c|c|}
\hline Gene & Clinical Features & $\begin{array}{l}\text { Selected } \\
\text { Ref. }\end{array}$ & Frequency \\
\hline DNMT3a & $\begin{array}{l}\text { The median OS among patients with Dnmt3a mutations was significantly shorter than wild type } \\
\text { patients. }\end{array}$ & [10] & $22.1 \%$ in $\mathrm{AML}$ \\
\hline TET2 & $\begin{array}{l}\text { In the European Leukemia Net (ELN) favorable-risk group, TET2-mutated patients had shorter EFS (EFS; } p \\
<0.001) \text { because of a lower CR rate }(p=0.007) \text {, and shorter DFS }(p=0.003) \text {, and also had shorter OS } \\
(p=0.001) \text { compared with TET2-wild type patients. (TET2 mutations were not associated with } \\
\text { outcomes in the ELN intermediate-l-risk group.) }\end{array}$ & {$[21]$} & $23 \%$ in CN-AML \\
\hline $\mathrm{IDH} 1$ & $\begin{array}{l}\text { IDH } 1 \text { mutation was associated with normal cytogenetics, a higher RR and a shorter OS. Prognosis was } \\
\text { adversely affected by IDH1 mutations with trend for shorter OS }(p=0.110) \text {, a shorter EFS }(p<0.003) \\
\text { and a higher cumulative risk for relapse }(p=0.001) \text {. Clear prevalence in intermediate risk karyotype } \\
\text { group }(10.4 \%, p<0.001) \text {. }\end{array}$ & {$[25-27]$} & 6.6-9.6\% in AML \\
\hline $\mathrm{IDH} 2$ & $\begin{array}{l}\text { In IDH2 mutation CN-AML patients, there is a higher risk of induction failure, a higher RR and shorter } \\
\text { OS. }\end{array}$ & {$[25,26]$} & $3.0-8.7 \%$ in $\mathrm{AML}$ \\
\hline NPM1 & $\begin{array}{l}\text { The analysis of the clinical impact in } 4 \text { groups (NPM1 and FLT3-ITD single mutants, double mutants, } \\
\text { and wild-type for both) revealed that patients having only an NPM1 mutation had a significantly better } \\
\text { OS and DFS and a lower cumulative incidence of relapse. }\end{array}$ & {$[28,29]$} & $\begin{array}{l}27.5-35.2 \% \text { in AML } \\
45.7-53 \% \text { in CN-AML }\end{array}$ \\
\hline ASXL1 & $\begin{array}{l}\text { Patients with ASXL1 mutations had a shorter OS than patients without, but the mutation was not an } \\
\text { independent adverse prognostic factor in multivariate analysis. }\end{array}$ & [39] & $10.8 \%$ in $\mathrm{AML}$ \\
\hline WT1 & $\begin{array}{l}\text { Multivariate analysis demonstrated that the WT1 mutation was an independent poor prognostic factor } \\
\text { for OS and RFS among total patients and the CN-AML group. }\end{array}$ & {$[41,42]$} & $\begin{array}{l}8.3-10.7 \% \text { in CN-AML } \\
6.8 \% \text { in de novo } \\
\text { non-M3 AML }\end{array}$ \\
\hline
\end{tabular}

genomic DNA compared with bone marrow samples from healthy controls [20]. Metzeler et al. [21] recently analyzed 427 patients with $\mathrm{CN}-\mathrm{AML}$, and revealed that TET2 mutations were detected in 95 of 418 (23\%) of the patients, and associated with older age $(\mathrm{p}<0.001)$ and higher pretreatment white blood cell counts $(\mathrm{p}=$ 0.04 ) compared with wild-type TET2. IDH1 and IDH2 mutations were less frequent in TET2-mutated patients than in TET2-wild-type patients $(\mathrm{p}<0.001)$, suggesting that these mutations are mutually exclusive. They also observed a trend toward a higher prevalence of $\mathrm{C} / \mathrm{EBP} \alpha$ mutations among TET2-mutated patients $(\mathrm{p}=0.07)$ [21]. In the European Leukemia Net (ELN) favorablerisk group (patients with $\mathrm{CN}$-AML who have mutated CEBP $\alpha$ and/or mutated NPM1 without FLT3-ITD), TET2-mutated patients had shorter event-free survival (EFS) $(\mathrm{p}<0.001)$, because of a lower complete remission $(\mathrm{CR})$ rate $(\mathrm{p}=0.007)$, shorter disease-free survival (DFS) $(\mathrm{p}=0.003)$ and shorter OS $(\mathrm{p}=0.001)$ compared with TET2-wild-type patients (Table 1 ). TET2 mutations were not associated with outcomes in the ELN intermediate-I-risk group (CN-AML with wild-type CEBP $\alpha$ and wild-type NPM1 and/or FLT3-ITD). In multivariate models, TET2 mutations were associated with shorter EFS $(p=0.004)$, lower CR rate $(p=0.03)$ and shorter DFS ( $p=0.05$ ) only among favorable-risk CN-AML patients [21]. Abdel-Wahab et al. [22] evaluated the mutational statuses of TET1, TET2 and TET3 in myeloproliferative neoplasms (MPNs), CMML and AML. They identified TET2 mutations in 27 of $354 \mathrm{MPN}$ patients (7.6\%), 29 of $69 \mathrm{CMML}$ patients (42\%), 11 of 91 AML patients (12\%) and 1 of 28 M7 AML patients
(3.6\%). Although they identified several single nucleotide polymorphisms in TET1 and TET3, they did not identify somatic TET1 or TET3 mutations in 96 MPN patients examined.

\section{IDH1 and IDH2 mutations}

Mardis et al. [3] used massively parallel DNA sequencing to obtain a very high level of coverage of a primary, cytogenetically normal, de novo genome for AML with minimal maturation (AML M1) and a matched normal skin genome, and identified 12 acquired mutations within the coding sequences of genes and 52 somatic point mutations in conserved or regulatory portions of the genome. Many of these were mutations that had already been identified, such as those in NRAS and NPM1, but they also found novel mutations of the IDH1 gene [3]. They further found that IDH1 gene mutations were present in 15 of 187 AML genomes and strongly associated with a normal cytogenetic status. IDH1 and IDH2 function at a crossroads involving cellular metabolism in lipid synthesis, cellular defense against oxidative stress, oxidative respiration and oxygen-sensing signal transduction [23]. Recently, AML patients harboring IDH1 and IDH2 mutations were found to show aberrant hypermethylation [24]. In fact, these mutations led to the production of an abnormal cellular metabolite, 2-hydroxyglutarate, which can inhibit the hydroxylation of $5-\mathrm{mC}$ by TET2 [24]. Consistent with Metzeler et al. [21], IDH1 and IDH2 mutations were mutually exclusive with TET2 mutations ( $\mathrm{p}=$ 0.009) [24]. Boissel et al. [25] analyzed the prognosis of patients with IDH1 mutations and IDH2 mutations in a 
cohort of 520 adults with AML homogeneously treated in the French Acute Leukemia French Association (ALFA)-9801 and -9802 trials. The prevalences of IDH1 mutations and IDH2 mutations were $9.6 \%$ and $3.0 \%$, respectively, and the mutations were mostly associated with $\mathrm{CN}$-AML. In patients with CN-AML, IDH1 mutations were associated with higher risk of relapse (RR) and shorter OS (Table 1). In CN-AML patients with IDH2 mutations, they observed a higher risk of induction failure, higher RR and shorter OS. Similar results were reported by Paschka et al. [26], who evaluated 805 adults with AML enrolled in the German-Austrian AML study group, and found IDH mutations in 129 patients (16.0\%), IDH1 mutations in 61 patients $(7.6 \%)$ and IDH2 mutations in 70 patients $(8.7 \%)$. These two reports both suggest the presence of interactions between IDH mutations and the genotype of mutated NPM1 without FLT3-ITD. They also both demonstrated that IDH mutations in AML are associated with a poor prognosis. Schnittger et al. [27] conducted a larger study. They analyzed IDH1R132 mutations in 1414 AML patients, and detected IDH1 mutations in $6.6 \%$ of the patients, with a clear prevalence in the intermediaterisk karyotype group $(10.4 \%$; $p<0.001)$. They also showed that IDH1 mutations had strong associations not only with NPM1 mutations ( $p<0.001)$, but with MLL-partial tandem duplicaton (PTD) as well ( $\mathrm{p}=$ 0.020) (Table 1 ). In addition, they revealed that the prognosis was adversely affected by IDH1 mutations with trends for shorter OS $(\mathrm{p}=0.110)$, shorter EFS ( $\mathrm{p}<$ $0.003)$ and higher cumulative RR ( $\mathrm{p}=0.001)$ (Table 1$)$.

\section{NPM1 mutations}

Falini et al. [4] described abnormal localization of NPM1 in AML patients. Cytoplasmic NPM1 was detected in 208 of 591 specimens (35.2\%) from patients with primary AML, but not in 135 secondary AML specimens or in 980 hematopoietic or extrahematopoietic neoplasms other than AML [4]. Thiede et al. [28] performed a larger study. They investigated 1485 AML patients for NPM1 exon 12 mutations, and found that the C-terminus of this protein was mutated in approximately $27.5 \%$ of the patients. NPM1 mutations were more prevalent in patients with a normal karyotype (324 of $709 ; 45.7 \%)$ than in patients with karyotype abnormalities (58 of 686; 8.5\%; $\mathrm{p}<0.001$ ). They suggested that NPM1 mutations are strongly associated with FLT3-ITD mutations in patients with a normal karyotype (mutated NPM1/FLT3-ITD, 43.8\% vs. wild-type NPM1/FLT3ITD, 19.9\%; $\mathrm{p}<0.001$ ) [28]. Analyses of the clinical impacts in four groups (NPM1 single mutants, FLT3ITD single mutants, NPM1/FLT3-ITD double mutants, and wild-type for both) revealed that patients with only NPM1 mutations had significantly better OS and DFS and a lower cumulative incidence of relapse [28] (Table 1). Schlenk et al. [29] focused their analyses on CNAML patients. Among 872 patients examined, they found that $53 \%$ of the patients had NPM1 mutations. In addition, 31\% had FLT3-ITD, 11\% had FLT3-TKD, 13\% had $\mathrm{C} / \mathrm{EBP} \alpha$ mutations, $7 \%$ had MLL-PTD and 13\% had NRAS mutations. They further demonstrated that FLT3-ITD $(\mathrm{p}<0.001)$ and FLT3-TKD mutations $(\mathrm{p}=$ 0.03 ) were significantly associated with NPM1 mutations, while NRAS mutations were not $(\mathrm{p}=0.46)$.

NPM1 is thought to have relevant roles in diverse cellular functions, including ribosome biogenesis, centrosome duplication, DNA repair and response to stress [30]. NPM1 is also involved in the functions of p53 and p19ARF [31,32]. Li et al. [33] demonstrated that wildtype NPM1 protects hematopoietic cells against p53induced apoptosis under conditions of cellular stress. Therefore, it is possible that failure of the mutated NPM1 to protect cells may make them more sensitive to high-level genotoxic stress induced by chemotherapy. Consequently, it is possible to speculate that patients with mutated NPM1 have a better prognosis.

\section{ASXL1 mutations}

The additional sex comb-like 1 (ASXL1) gene belongs to a family with three identified members that encode poorly characterized proteins involved in the regulation of chromatin remodeling. The ASXL proteins contain a C-terminal plant homeodomain (PHD) finger and belong to the polycomb and trithorax complexes that regulate the genetic program of stem cells. ASXL1 is involved in the regulation of histone methylation by cooperation with heterochromatin protein-1 to modulate the activity of lysine-specific demethylase (LSD) 1 [34], a histone demethylase for H3K4 and H3K9 that is also important for global DNA methylation [35]. However, the hematopoietic function of ASXL1 is still unclear, since an ASXL1 knockout mouse model shows only a mild hematopoietic phenotype [36]. In 2009, Gelsi-Boyer et al. [37] first identified mutations of ASXL1 in $40 \mathrm{MDS} / \mathrm{AML}$ samples using high-density comparative genomic hybridization arrays. They found mutations in the ASXL1 gene in 4 of 35 MDS patients (11\%) and 17 of 39 CMML patients (43\%). Another study identified mutations of the ASXL1 gene in 12 of 63 (19\%) secondary AML patients transformed from MPN [38]. Recently, Chou et al. [39] examined ASXL1 gene mutations in exon 12 in 501 adults with de novo AML. ASXL1 mutations were detected in 54 patients (10.8\%), with $8.9 \%$ among patients with a normal karyotype and $12.9 \%$ among patients with abnormal cytogenetics. The mutations were closely associated with older age, male sex, isolated trisomy 8, RUNX1 mutations, and expression of human leukocyte antigen-DR and 
CD34, but inversely associated with $\mathrm{t}(15 ; 17)$, complex cytogenetics, FLT3-ITD, NPM1 mutations, WT1 mutations and expression of CD33 and CD15. Patients with ASXL1 mutations had shorter OS than patients without such mutations, but the mutations were not an independent adverse prognostic factor in a multivariate analysis [39] (Table 1).

\section{WT1 mutations}

Although mutations of WT1 were first discovered in hematological malignancies more than a decade ago, the precise roles of WT1 in normal and malignant hematopoiesis remain elusive [40]. It has been implicated in the regulation of cell survival, proliferation and differentiation, and may function as both a tumor suppressor and an oncogene [40]. Paschka et al. [41] analyzed 196 adults aged $<60$ years with newly diagnosed primary CN-AML, who were treated similarly with Cancer and Leukemia Group B (CALGB) protocols 9621 and 19808, for WT1 mutations in exons 7 and 9. As a result, 21 patients $(10.7 \%)$ harbored WT1 mutations. The patients with WT1 mutations had worse DFS ( $\mathrm{p}<0.001)$ and OS $(\mathrm{p}<0.001)$ than patients with wild-type WT1. Subsequently, Hou et al. [42] examined the clinical implications of WT1 mutations in 470 de novo non-M3 AML patients aged $\geq 15$ years, and their stability during the clinical course. WT1 mutations were identified in $6.8 \%$ of the total patients and $8.3 \%$ of the younger patients with CN-AML. The WT1 mutations were closely associated with younger age $(\mathrm{p}<0.01)$, French-AmericanBritish M6 subtype $(\mathrm{p}=0.006)$ and $\mathrm{t}(7 ; 11)(\mathrm{p} 15 ; \mathrm{p} 15)$ ( $\mathrm{p}$ $=0.003)$. A multivariate analysis demonstrated that WT1 mutations comprised an independent poor prognostic factor for OS and relapse-free survival (RFS) among the total patients and the CN-AML patients. In addition, among 32 patients with WT1 mutations, the most frequently associated molecular event was FLT3ITD (9 cases) [42]. Becker et al. [43] investigated 243 older ( $\geq 60$ years) primary CN-AML patients, and found that WT1-mutated patients $(7 \%)$ had more frequent FLT3-ITD $(\mathrm{p}<0.001)$ and shorter OS ( $\mathrm{p}=0.08)$ compared with WT1-wild-type patients. The clinical features of the unclassified mutations are summarized in Table 1.

\section{Class I mutations (FLT3, PTPN11, NRAS, KIT and CBL mutations)}

\section{FLT3 mutations}

FLT3 is a type III RTK and since the first description [44], numerous studies have confirmed and extended the findings that FLT3 mutations are currently one of the most frequent single mutations identified in AML. ITD mutations of the FLT3 gene occur in approximately 21-24\% of adult AML patients [14,28] while activating point mutations of the FLT3-TKD, mainly at Asp 835, are found in approximately 5-7\% of AML patients [1,45-48]. The most significant impacts of an ITD are its associations with a higher leukocyte count, increased RR, decreased DFS and decreased OS, which have been reported in most studies of children and adults aged < 60 years [49]. Several groups found that an ITD is a significant predictive factor for an adverse outcome in multivariate analyses [49-52] (Table 2). Bacher et al. [46] performed a large study involving 3082 patients with newly diagnosed AML, and analyzed the mutational status and clinical significance of the FLT3-TKD. They observed FLT3-TKD mutations in 147 patients (4.8\%). Unlike FLT3-ITD, the prognosis was not influenced by FLT3-TKD mutations in a total cohort of 1720 cases where follow up-data were available (97 mutated FLT3TKD cases and 1623 wild-type FLT3 cases) (Table 2). In addition, Ozeki et al. [53] reported that even in patients with wild-type FLT3, a clear tendency for worse OS was found in patients with high FLT3 expression (5 of 86 patients without FLT3-ITD). Another group observed a similar result for a tendency toward lower OS (12 of 24 patients, $\mathrm{p}=0.059$ ) and EFS (7 of 20 patients, $\mathrm{p}=$ 0.087 ) in the group with high FLT3 expression [54] (Table 2).

FLT3-ITD mutations are correlated with certain cytogenetic subgroups. Among acute promyelocytic leukemia patients with PML-RAR $\alpha$, it was reported that 30$50 \%$ of patients had FLT3 mutations [55-57]. In addition, frequent $(88 \sim 90 \%)$ co-occurrence was reported in patients with $\mathrm{t}(6 ; 9)$ and FLT3-ITD $[55,58]$. Similarly, FLT3-ITD was frequently found in patients with MLLPTD [59]. The rate of MLL-PTD in FLT3-ITD-positive patients was significantly higher than that in FLT3-ITDnegative patients [16 of $184(8.7 \%)$ vs. 32 of $772(4.1 \%)$; $\mathrm{p}=0.025$ ] [59]. In analyses involving 353 adult de novo AML patients, Carnicer et al. [60] found cooperative mutations of FLT3-TKD with $\mathrm{CBF} \beta / \mathrm{MYH} 11$ rearrangement (4 of 15 patients) and C/EBP $\alpha$ with FLT3-ITD (2 of 82 patients). Collectively, FLT3 mutations play a key role in leukemogenesis by functionally cooperating with other molecules.

\section{PTPN11 mutations}

SHP-2 is a cytoplasmic protein tyrosine phosphatase (PTP) that contains two Src homology 2 (SH2) domains. Although PTPs are generally considered to be negative regulators, SHP-2 is unusual in that it promotes the activation of the RAS-MAPK signaling pathway through receptors for various growth factors and cytokines. Mutations in the protein tyrosine phosphatase nonreceptor type 11 (PTPN11), as the human SHP-2 gene, have been shown to produce dominant active mutants in vitro [61]. Hou et al. [62] investigated the prevalence and clinical relevance of mutations of PTPN11 and their 
Table 2 Clinical features of gene mutations in AML (class I mutations)

\begin{tabular}{|c|c|c|c|}
\hline Gene & Clinical Features & $\begin{array}{l}\text { Selected } \\
\text { Ref. }\end{array}$ & Frequency \\
\hline $\begin{array}{l}\text { FLT3 } \\
\text {-ITD }\end{array}$ & Association with a higher leukocyte count, increased RR, decreased DFS, and decreased OS. & {$[14,28,49-52]$} & $21-24 \%$ in $\mathrm{AML}$ \\
\hline$-T K D$ & Prognosis was not influenced. & [46] & $5-7 \%$ in $\mathrm{AML}$ \\
\hline -WT & Clear tendencies for worse OS and EFS were found in patients with high FLT3 expression. & {$[53,54]$} & \\
\hline PTPN11 & $\begin{array}{l}\text { No prognostic significance. However, subgroup analysis did reveal that the PTPN11 mutation was a } \\
\text { poor risk factor for OS of AML patients who did not have NPM1 mutations. }\end{array}$ & [62] & $5.1 \%$ in $\mathrm{AML}$ \\
\hline NRAS & No significant prognostic impact for OS, EFS and DFS. & [64] & $10.3 \%$ in $\mathrm{AML}$ \\
\hline KIT & $\begin{array}{l}\text { Adversely affect OS in AML with inv(16). Adverse impact of mutation of KIT on RR in } \mathrm{t}(8 ; 21) \mathrm{AML} \text {. } \\
\mathrm{KIT} \text { mutations had an independent negative impact on OS and EFS in patients with } \mathrm{t}(8 ; 21) \text { but not } \\
\text { in patients with a normal karyotype. }\end{array}$ & {$[66,68,69]$} & $\begin{array}{l}1.7 \% \text { in } \mathrm{AML} \\
22-45 \% \text { in } \mathrm{t}(8 ; 21) 29- \\
48 \% \text { in inv(16) }\end{array}$ \\
\hline CBL & n. d. & {$[72,73]$} & $\begin{array}{l}1.1 \% \text { in } \mathrm{AML} / \mathrm{MDS} \\
16 \% \text { in inv(16)AML }\end{array}$ \\
\hline
\end{tabular}

associations with other genetic changes in 272 consecutive patients with primary AML. Among 14 patients with PTPN11 mutations (5.1\%), none had FLT3-ITD. On the other hand, 6 of 13 patients with PTPN11 mutations had concurrent NPM1 mutations (46.2\%) [62], suggesting that PTPN11 is a class I mutation molecule similar to the case for FLT3. They further revealed that PTPN11 mutations had no prognostic significance. The CR rate (75\% vs. $62 \%)$ and median OS (13 \pm 8.95 vs. $25.5 \pm 6.54$ months) were similar between patients with and without PTPN11 mutations. However, subgroup analyses did reveal that PTPN11 mutations comprised a poor risk factor for OS of AML patients without NPM1 mutations ( $\mathrm{p}=0.001)[62]$ (Table 2).

\section{NRAS mutations}

Ras oncogenes encode a family of guanine nucleotidebinding proteins that regulate signal transduction upon binding to a variety of membrane receptors, including KIT and FLT3, and play important roles in proliferation, differentiation and apoptosis [63]. There are three functional RAS genes: NRAS, KRAS and HRAS. The RAS genes, especially $N R A S$, are frequently affected by mutations in AML. Bacher et al. [64] analyzed 2502 patients with AML, and found that 257 patients (10.3\%) had NRAS mutations. The subgroups with inv(16) and inv (3) showed significantly higher frequencies of NRAS mutations. In contrast, NRAS mutations were significantly underrepresented in $\mathrm{t}(15 ; 17)$ (2 of $102 ; 2 \% ; \mathrm{p}=$ $0.005)$. They did not find significant prognostic impacts of NRAS mutations for OS, EFS and DFS (Table 2).

\section{KIT mutations}

KIT is a member of the type III RTK family, and ligandindependent activation of KIT can be caused by gain-offunction mutations that have been reported in core binding factor (CBF) leukemia, and AML subgroups with $\operatorname{inv}(16)$ and $t(8 ; 21)$ [65-67], which result in expression of the abnormal fusion genes CBF $\beta / \mathrm{MYH} 11$ and RUNX1/ETO, respectively. Paschka et al. [68] analyzed 61 adults with CBF leukemia for KIT mutations. Among patients with inv(16), 29.5\% had KIT mutations. Among patients with $\mathrm{t}(8 ; 21), 22 \%$ had KIT mutations. Mutations of the $c$-kit gene in both exon 17 and exon 8 appeared to adversely affect OS in AML with inv(16). They also observed an adverse impact of KIT mutations on RR in $\mathrm{t}(8 ; 21)$ AML patients (Table 2). Cairoli et al. [65] reported that among 42 patients with $\mathrm{t}(8 ; 21), 19$ patients $(45.2 \%)$ had KIT mutations, whereas among 25 patients with inv(16), 12 patients $(48.0 \%)$ had KIT mutations. Schnittger et al. [66] analyzed 1940 randomly selected AML patients and revealed that 33 patients (1.7\%) were positive for KIT mutations in codon D816. Of these 33 patients, 8 patients $(24.2 \%)$ had $t(8 ; 21)$, which was significantly higher compared with the subgroup without D816 mutations. They revealed that KIT mutations had independent negative impacts on the median OS (304 vs. 1836 days; $\mathrm{p}=0.006$ ) and median EFS (244 vs. 744 days; $p=0.003)$ in patients with $t(8$; 21) but not in patients with a normal karyotype (Table 2 ). They also revealed that other activating mutations, like FLT3 and NRAS mutations, were very rarely detected in $t(8 ; 21)$ leukemia patients. On the contrary, in an analysis of 99 patients with $t(8 ; 21)$, Kuchenbauer et al. [69] reported that the frequent molecular aberrations with $\mathrm{t}(8 ; 21)$ were not only KIT D816 mutations (3 of 23 patients; $13 \%$ ) but also NRAS mutations ( 8 of 89 patients; $8.9 \%)$. Although the co-occurrence of NRAS mutations and AML1/ETO expression remains elusive, all of these reports suggest that KIT mutants play important roles in CBF leukemia, with negative impacts on the clinical course $[65,66,68,69]$.

\section{CBL mutations}

The Casitas B-cell lymphoma $(C B L)$ gene gives rise to the CBL protein, which has ubiquitin ligase activity and 
targets a variety of tyrosine kinases for degradation by ubiquitination [70]. CBL proteins also associate with the endocytic machinery and are thus important for the termination of RTK signaling [70]. CBL mutations were able to inhibit FLT3 internalization and ubiquitination [71]. In vitro experiments confirmed constitutive activation of the FLT3 pathway by the CBL mutants, and the phenotype of the altered cells resembled the phenotype of FLT3-mutated cells [72]. Reindl et al. [72] identified c-CBL gene exon $8 / 9$ deletion mutants in $1.1 \%$ of 279 patients with AML/MDS. All the patients with $\mathrm{CBL}$ mutations had CBF leukemia and chromosome $11 \mathrm{q}$ abnormalities [72]. In a series of 37 patients with newly diagnosed inv(16) AML, Haferlach et al. [73] detected CBL splicing mutations in 6 patients (16\%). The prevalence and features of these class I mutations are summarized in Table 2.

\section{Class II mutations (RUNX1 mutations, C/EBP $\alpha$ mutations and MLL rearrangement) RUNX1 mutations}

Runx1 is required for definitive hematopoiesis and is necessary for the differentiation of myeloid progenitor cells to granulocytes [74]. Recently, Gaidzik et al. [75] precisely studied the frequency, biologic features and clinical relevance of Runx1 mutations in AML. They found that RUNX1 gene mutations, which span exons $3,4,5$ and 8 , were present in 53 of 945 patients (5.6\%) with AML. RUNX1 mutations were associated with MLL-PTD ( $\mathrm{p}=0.0007)$ and IDH1/IDH2 mutations ( $\mathrm{p}$ $=0.03$ ), inversely correlated with NPM1 ( $<$ < 0.0001), and in trend with $\mathrm{CEBP} \alpha(\mathrm{p}=0.10)$ mutations. RUNX1 mutations predicted resistance to chemotherapy, as well as inferior EFS ( $\mathrm{p}<0.0001)$, RFS ( $\mathrm{p}=$ 0.022 ) and $\mathrm{OS}(\mathrm{p}=0.051)$. In multivariate analyses, RUNX1 mutations were an independent prognostic marker for shorter EFS ( $\mathrm{p}=0.007$ ) (Table 3). Tang et al. [76] examined 470 adult patients with de novo nonM3 AML. Among these patients, 63 distinct RUNX1 mutations were identified in 62 patients (13.2\%). They also revealed that the mutations were positively associated with MLL-PTD but negatively associated with $\mathrm{C} / \mathrm{EBP} \alpha$ and NPM1 mutations. Schnittger et al. [77] detected 164 RUNX1 mutations in 147 of 449 patients (32.7\%) with a normal karyotype or noncomplex chromosomal imbalances. RUNX1 mutations were most frequent in AML M0 (65.2\%) followed by M2 (32.4\%) and M1 (30.2\%). The molecular genetic markers most frequently associated with RUNX1 mutations were MLL-PTD (19.7\%), FLT3-ITD (16.3\%) and NRAS mutations (9.5\%). Multivariate analyses showed that RUNX1 mutations independently predicted an unfavorable prognosis for OS $(\mathrm{p}=0.029)$.

\section{$\mathrm{C} / \mathrm{EBP} \alpha$ mutations}

The transcription factor $\mathrm{C} / \mathrm{EBP} \alpha$ is crucial for the differentiation of granulocytes. $\mathrm{C} / \mathrm{EBP} \alpha$ inactivation may take place by acquired mutations, which may occur along the entire coding region. These mutations lead to increased translation of an alternative $30-\mathrm{kDa}$ form with dominant negative activity on the full-length $42-\mathrm{kDa}$ protein when they occur in the $\mathrm{N}$-terminus, while $\mathrm{C}$-terminal mutations result in deficient DNA binding and/or homodimerization activities [63,78]. As reviewed by Pabst and Mueller [79], mutations in the various portions of $\mathrm{C} /$ $\mathrm{EBP} \alpha$ have been reported to occur in 5-14\% of AML patients. Among patients with $\mathrm{C} / \mathrm{EBP} \alpha$ mutations, 91\% were in the CN-AML molecular high-risk group (FLT3ITD-positive and/or NPM1-wild-type), although they seemed to be associated with a good prognosis in AML with an intermediate-risk karyotype [80]. Compared with $\mathrm{C} / \mathrm{EBP} \alpha$-wild-type patients, patients with $\mathrm{C} / \mathrm{EBP} \alpha$ mutations showed a trend for a better CR rate (93\% vs. $77 \% ; \mathrm{p}=0.06)$ and significantly higher 5 -year rates of EFS (55\% vs. $17 \%$; p < 0.001$)$, DFS (53\% vs. $23 \%$; p = 0.001 ) and $\mathrm{OS}$ (58\% vs. $27 \%$; $=0.002$ ) [80] (Table 3 ). However, the reason why $\mathrm{C} / \mathrm{EBP} \alpha$ mutations confer a good prognosis remains unclear.

\section{MLL rearrangement}

Approximately 4-11\% of patients with AML present with rearrangement of the MLL (also known as ALL1 or HRX) gene as the result of a PTD within a single MLL allele [81]. This aberration tends to be frequent in AML patients without chromosomal abnormalities [81]. MLL is a $430-\mathrm{kDa}$ transcription factor with a complex structure that includes three AT-hook domains for DNA binding, a methyltransferase homology domain and a SET domain [81]. MLL is necessary for the maintenance for HOX gene expression [82]. The MLL SET domain can bind to the promoters of HOX genes [83]. Munoz et al. [84] examined 93 adult patients with de novo AML for the incidence and clinical features of MLLrearranged AMLs. As a result, they detected MLL rearrangement in 13 patients (14\%). In the FAB classification, there was a significantly higher percentage of M5 subtypes in the MLL-rearranged group. The MLL-rearranged patients had lower EFS $(p=0.001)$ and a higher probability of relapse $(p=0.07)$ than MLL-wild-type patients. The clinical features of these RUNX1 and C/ $\mathrm{EBP} \alpha$ mutations and MLL rearrangement are shown in Table 3.

\section{Conclusions}

The development of novel technologies has led to the identification of several important genetic mutations in AML. Along with the development of whole genome 
Table 3 Clinical features of gene mutations in AML (class II mutations)

\begin{tabular}{|c|c|c|c|}
\hline Gene & Clinical Features & $\begin{array}{l}\text { Selected } \\
\text { Ref. }\end{array}$ & Frequency \\
\hline$\overline{\text { Runx1 }}$ & $\begin{array}{l}\text { In multivariable analysis, RUNX1 mutations were an independent prognostic marker for shorter EFS. } \\
\text { Independent unfavorable prognosis for OS for RUNX1 mutation. }\end{array}$ & [75-77] & $\begin{array}{l}5.6 \% \text { in } \mathrm{AML} \\
13.2 \% \text { in de novo non- } \\
\mathrm{M} 3 \mathrm{AML} \\
32.7 \% \text { in } \mathrm{CN} \text { or } \\
\text { noncomplex karyotype } \\
\text { AML }\end{array}$ \\
\hline $\begin{array}{l}\mathrm{C} / \\
\mathrm{EBP} \alpha\end{array}$ & $\begin{array}{l}\text { C/EBP } \alpha \text { mutations had a trend for a better CR rate and significantly greater } 5 \text {-year rates of EFS, DFS } \\
\text { and OS. }\end{array}$ & {$[79,80]$} & $5-14 \%$ in $\mathrm{AML}$ \\
\hline $\begin{array}{l}\text { MLL } \\
\text { rearr. }\end{array}$ & $\begin{array}{l}\text { Patients with MLL rearrangement had a lower EFS and a higher probability of relapse than MLL } \\
\text { wild type patients. }\end{array}$ & [81] & $4-14 \%$ in $\mathrm{AML}$ \\
\hline
\end{tabular}

sequencing, it is probable that the major genetic aberrations have been almost completely identified. The next stage is to clarify the consequence of these molecular alterations, especially for the newly identified molecules.

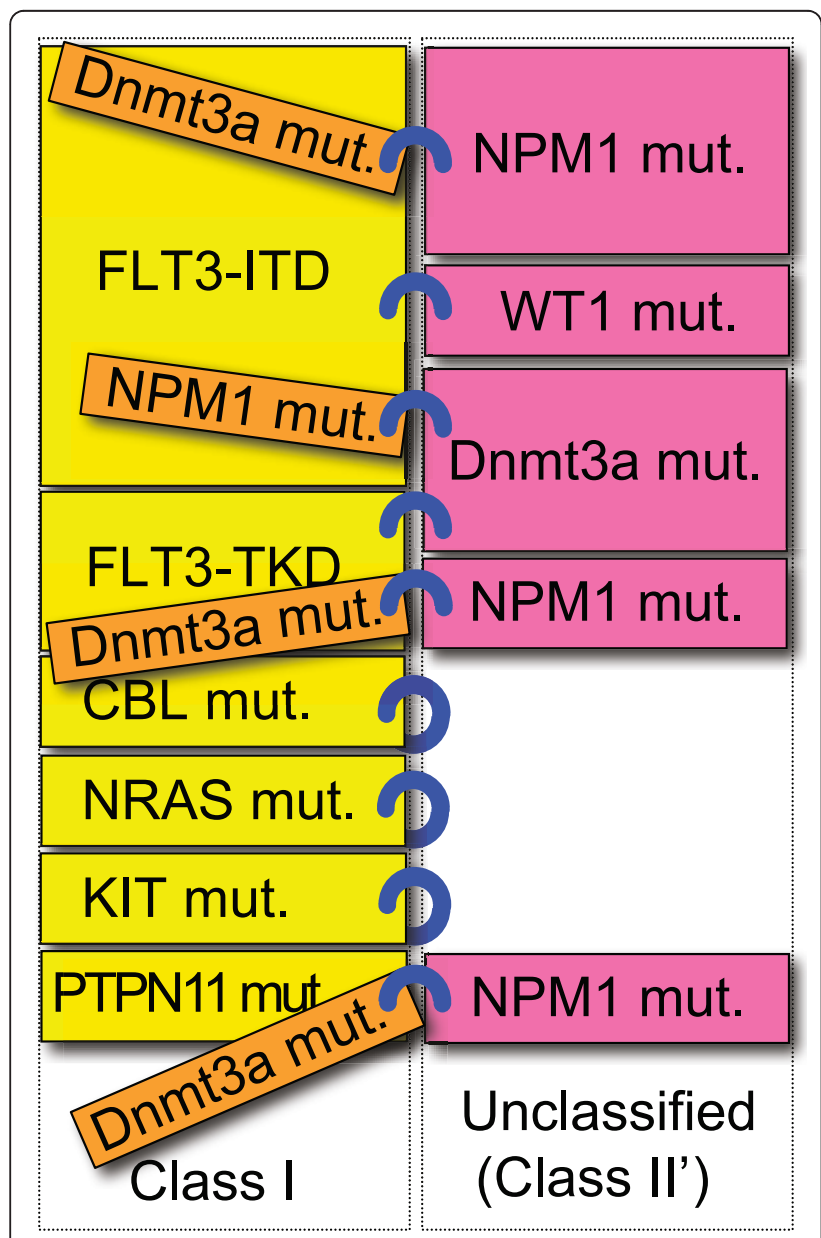

Figure 2 The combination model of class I and unclassified mutations in AML. Several unclassified mutations (NPM1, WT1, Dnmt3a) co-occur with several class I mutations. These may fall into putative class II mutations (termed "class II' mutations"), shown in pink boxes. Within these mutations, co-occurrences were observed between Dnmt3a, NPM1mutations (shown in orange boxes), therefore, these mutations may be exception of this model.
As described in this review, mutations in several newly identified genes, such as TET2 and IDH1/2, lead to the aberrant hypermethylation signature in AML cells [24]. In addition, there were alterations in the DNA methylation patterns and/or gene expression profiles, such as HOXB genes, in samples with DNMT3a mutations compared with those without such mutations [19]. Collectively, these recent findings strongly suggest a link between recurrent genetic alterations and aberrant epigenetic regulation, resulting in abnormal DNA methylation statuses in myeloid malignancies.

With the identification of novel genetic aberrations, increasing numbers of cooperative interactions of these genetic alterations have been discovered. These observations indicate that these unclassified mutations may fall into several subcategories. A revised model of these combinations, including "unclassified mutations" in AML is shown in Figure 2 and 3. In general, the mutations in the same category are mutually exclusive $[14,85]$. However, there are some exceptions. In "classical" class II mutations, co-occurrence was reported between RUNX1 mutations and MLL rearrangement [76] (Figure 1). Likewise, in unclassified mutations, co-occurrences were observed among Dnmt3a, NPM1 and IDH1/2 mutations $[10,25,26]$. Dnmt3a and NPM1 mutations co-occur with both classical class I and class II mutations, therefore, these mutations may not be simply categorized into "classical” class I or class II mutations, but it would fall into new category of mutations. Further characterization of these mutations, not only from clinical studies, but also from studies of transgenic animals may be needed.

For these several years, there are admirable progress for the identification of the molecular prognostic markers for CN-AML [86]. Based on these genetic alterations, several signal transduction pathway inhibitors and DNA methyltransferase inhibitors (decitabine, azacitidine) were reported for AML treatment [87]. The newly identified combinations of genetic aberrations will lead to a refined disease classification and to the development of more rational, epigenetic or signal transduction pathway-targeted therapies. 


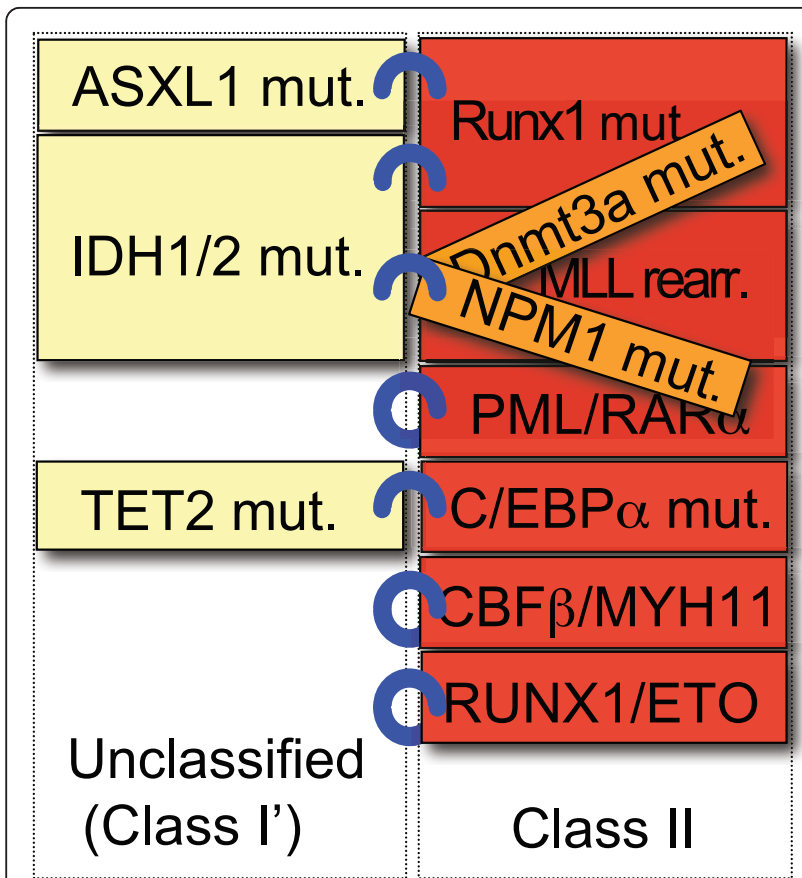

Figure 3 The combination model of class II and unclassified mutations in AML. Several unclassified mutations (ASXL1, IDH1/2, TET2) co-occur with several class II mutations. These may fall into putative class I mutations (termed "class I' mutations"), shown in light yellow boxes. IDH1/2 mutations co-occurred not only with MLL rearrangement, but also Dnmt3a and NPM1 mutations, as shown in orange boxes.

\section{Acknowledgements}

I appreciate Dr. Toshio Okazaki (Kitasato University) for many helpful suggestions for preparing figures. I thank Dr. Alison Sherwin (Edanz group Itd.) for English editing and critical reading in the preparation of this manuscript. I also thank Dr. Takeo Takahashi (Yaotome Clinic) for helpful advice on English language in the revision. This work was supported in part by Grants-in-Aid for Scientific Research (No. 23590687) from the Ministry of Education, Science and Culture, Japan, the Takeda Sceince Foundation, a foundation from Kitasato University School of Allied Health Sciences (Grantin-Aid for Research Project, No. 2011-1001).

\section{Authors' information}

Professor and Chief, the Division of Molecular Hematology, Kitasato University Graduate School of Medical Sciences and the Division of Hematology, Kitasato University School of Allied Health Sciences, Sagamihara, Japan

\section{Competing interests}

The author declares that they have no competing interests.

Received: 25 July 2011 Accepted: 14 September 2011 Published: 14 September 2011

\section{References}

1. Takahashi S: Downstream molecular pathways of FLT3 in the pathogenesis of acute myeloid leukemia: biology and therapeutic implications. J Hematol Oncol 2011, 4:13.

2. Dohner K, Dohner H: Molecular characterization of acute myeloid leukemia. Haematologica 2008, 93:976-982.

3. Mardis ER, Ding L, Dooling DJ, Larson DE, McLellan MD, Chen K, Koboldt DC, Fulton RS, Delehaunty KD, McGrath SD, et al: Recurring mutations found by sequencing an acute myeloid leukemia genome. $N$ Engl J Med 2009, 361:1058-1066.

4. Falini B, Mecucci C, Tiacci E, Alcalay M, Rosati R, Pasqualucci L, La Starza R, Diverio D, Colombo E, Santucci A, et al: Cytoplasmic nucleophosmin in acute myelogenous leukemia with a normal karyotype. $N$ Engl I Med 2005, 352:254-266

5. Byrd JC, Mrozek K, Dodge RK, Carroll AJ, Edwards CG, Arthur DC, Pettenati MJ, Patil SR, Rao KW, Watson MS, et al: Pretreatment cytogenetic abnormalities are predictive of induction success, cumulative incidence of relapse, and overall survival in adult patients with de novo acute myeloid leukemia: results from Cancer and Leukemia Group B (CALGB 8461). Blood 2002, 100:4325-4336

6. Grimwade D, Hills RK, Moorman AV, Walker $\mathrm{H}$, Chatters $\mathrm{S}$, Goldstone $\mathrm{AH}$, Wheatley K, Harrison CJ, Burnett AK: Refinement of cytogenetic classification in acute myeloid leukemia: determination of prognostic significance of rare recurring chromosomal abnormalities among 5876 younger adult patients treated in the United Kingdom Medical Research Council trials. Blood 2010, 116:354-365.

7. Foran JM: New prognostic markers in acute myeloid leukemia: perspective from the clinic. Hematology Am Soc Hematol Educ Program 2010, 47-55

8. Thiede C, Steudel C, Mohr B, Schaich M, Schakel U, Platzbecker U, Wermke M, Bornhauser M, Ritter M, Neubauer A, et al: Analysis of FLT3activating mutations in 979 patients with acute myelogenous leukemia: association with $F A B$ subtypes and identification of subgroups with poor prognosis. Blood 2002, 99:4326-4335.

9. Lowenberg B: Diagnosis and prognosis in acute myeloid leukemia-the art of distinction. N Engl J Med 2008, 358:1960-1962.

10. Ley TJ, Ding L, Walter MJ, McLellan MD, Lamprecht T, Larson DE, Kandoth C, Payton JE, Baty J, Welch J, et al: DNMT3A Mutations in Acute Myeloid Leukemia. N Engl J Med 2010, 363:2424-2433.

11. Delhommeau F, Dupont S, Della Valle V, James C, Trannoy S, Masse A, Kosmider O, Le Couedic JP, Robert F, Alberdi A, et al: Mutation in TET2 in myeloid cancers. N Engl J Med 2009, 360:2289-2301.

12. Wheeler DA, Srinivasan M, Egholm M, Shen Y, Chen L, McGuire A, He W, Chen YJ, Makhijani V, Roth GT, et al: The complete genome of an individual by massively parallel DNA sequencing. Nature 2008, 452:872-876

13. Vardiman JW, Thiele J, Arber DA, Brunning RD, Borowitz MJ, Porwit A, Harris NL, Le Beau MM, Hellstrom-Lindberg E, Tefferi A, Bloomfield CD: The 2008 revision of the World Health Organization (WHO) classification of myeloid neoplasms and acute leukemia: rationale and important changes. Blood 2009, 114:937-951.

14. Gilliland DG, Griffin JD: The roles of FLT3 in hematopoiesis and leukemia. Blood 2002, 100:1532-1542.

15. Frohling S, Scholl C, Gilliland DG, Levine RL: Genetics of myeloid malignancies: pathogenetic and clinical implications. J Clin Oncol 2005, 23:6285-6295.

16. Kelly LM, Gilliland DG: Genetics of myeloid leukemias. Annu Rev Genomics Hum Genet 2002, 3:179-198.

17. Esteller M: Epigenetics in cancer. N Engl I Med 2008, 358:1148-1159.

18. Walter MJ, Ding L, Shen D, Shao J, Grillot M, McLellan M, Fulton R, Schmidt H, Kalicki-Veizer J, O'Laughlin M, et al: Recurrent DNMT3A mutations in patients with myelodysplastic syndromes. Leukemia 2011.

19. Yan XJ, Xu J, Gu ZH, Pan CM, Lu G, Shen Y, Shi JY, Zhu YM, Tang L, Zhang $X W$, et al: Exome sequencing identifies somatic mutations of DNA methyltransferase gene DNMT3A in acute monocytic leukemia. Nat Genet 2011, 43:309-315.

20. Ko M, Huang Y, Jankowska AM, Pape UJ, Tahiliani M, Bandukwala HS, An J, Lamperti ED, Koh KP, Ganetzky R, et al: Impaired hydroxylation of 5methylcytosine in myeloid cancers with mutant TET2. Nature 2010, 468:839-843.

21. Metzeler KH, Maharry K, Radmacher MD, Mrozek K, Margeson D, Becker H, Curfman J, Holland KB, Schwind S, Whitman SP, et al: TET2 mutations improve the new European LeukemiaNet risk classification of acute myeloid leukemia: a Cancer and Leukemia Group B study. J Clin Oncol 2011, 29:1373-1381.

22. Abdel-Wahab O, Mullally A, Hedvat C, Garcia-Manero G, Patel J, Wadleigh M, Malinge S, Yao J, Kilpivaara O, Bhat R, et al: Genetic characterization of TET1, TET2, and TET3 alterations in myeloid malignancies. Blood 2009, 114:144-147. 
23. Reitman ZJ, Yan H: Isocitrate dehydrogenase 1 and 2 mutations in cancer: alterations at a crossroads of cellular metabolism. J Natl Cancer Inst 2010, 102:932-941.

24. Figueroa ME, Abdel-Wahab O, Lu C, Ward PS, Patel J, Shih A, Li Y, Bhagwat N, Vasanthakumar A, Fernandez HF, et al: Leukemic IDH1 and $\mathrm{IDH} 2$ mutations result in a hypermethylation phenotype, disrupt TET2 function, and impair hematopoietic differentiation. Cancer Cell 2010, 18:553-567.

25. Boissel N, Nibourel O, Renneville A, Gardin C, Reman O, Contentin N, Bordessoule D, Pautas C, de Revel T, Quesnel B, et al: Prognostic impact of isocitrate dehydrogenase enzyme isoforms 1 and 2 mutations in acute myeloid leukemia: a study by the Acute Leukemia French Association group. J Clin Oncol 2010, 28:3717-3723.

26. Paschka P, Schlenk RF, Gaidzik VI, Habdank M, Kronke J, Bullinger L, Spath D, Kayser S, Zucknick M, Gotze K, et al: IDH1 and IDH2 mutations are frequent genetic alterations in acute myeloid leukemia and confer adverse prognosis in cytogenetically normal acute myeloid leukemia with NPM1 mutation without FLT3 internal tandem duplication. J Clin Oncol 2010, 28:3636-3643.

27. Schnittger S, Haferlach C, Ulke M, Alpermann T, Kern W, Haferlach T: IDH1 mutations are detected in $6.6 \%$ of $1414 \mathrm{AML}$ patients and are associated with intermediate risk karyotype and unfavorable prognosis in adults younger than 60 years and unmutated NPM1 status. Blood 2010, 116:5486-5496

28. Thiede C, Koch S, Creutzig E, Steudel C, Illmer T, Schaich M, Ehninger G: Prevalence and prognostic impact of NPM1 mutations in 1485 adult patients with acute myeloid leukemia (AML). Blood 2006, 107:4011-4020

29. Schlenk RF, Dohner K, Krauter J, Frohling S, Corbacioglu A, Bullinger L, Habdank M, Spath D, Morgan M, Benner A, et al: Mutations and treatment outcome in cytogenetically normal acute myeloid leukemia. N Engl J Med 2008, 358:1909-1918.

30. Colombo E, Alcalay M, Pelicci PG: Nucleophosmin and its complex network: a possible therapeutic target in hematological diseases. Oncogene 2011, 30:2595-2609.

31. Colombo E, Marine JC, Danovi D, Falini B, Pelicci PG: Nucleophosmin regulates the stability and transcriptional activity of p53. Nat Cell Biol 2002, 4:529-533

32. Bertwistle D, Sugimoto $M$, Sherr CJ: Physical and functional interactions of the Arf tumor suppressor protein with nucleophosmin/B23. Mol Cell Biol 2004, 24:985-996.

33. Li J, Zhang X, Sejas DP, Pang Q: Negative regulation of p53 by nucleophosmin antagonizes stress-induced apoptosis in human normal and malignant hematopoietic cells. Leuk Res 2005, 29:1415-1423.

34. Lee SW, Cho YS, Na JM, Park UH, Kang M, Kim EJ, Um SJ: ASXL1 represses retinoic acid receptor-mediated transcription through associating with HP1 and LSD1. J Biol Chem 2010, 285:18-29.

35. Wang J, Hevi S, Kurash JK, Lei H, Gay F, Bajko J, Su H, Sun W, Chang H, $\mathrm{Xu}$ G, et al: The lysine demethylase LSD1 (KDM1) is required for maintenance of global DNA methylation. Nat Genet 2009, 41:125-129.

36. Fisher $\mathrm{CL}$, Pineault $\mathrm{N}$, Brookes $\mathrm{C}$, Helgason $\mathrm{CD}$, Ohta $\mathrm{H}$, Bodner $\mathrm{C}$, Hess JL, Humphries RK, Brock HW: Loss-of-function Additional sex combs like 1 mutations disrupt hematopoiesis but do not cause severe myelodysplasia or leukemia. Blood 2010, 115:38-46.

37. Gelsi-Boyer V, Trouplin V, Adelaide J, Bonansea J, Cervera N, Carbuccia N, Lagarde A, Prebet T, Nezri M, Sainty D, et al: Mutations of polycombassociated gene ASXL1 in myelodysplastic syndromes and chronic myelomonocytic leukaemia. Br J Haematol 2009, 145:788-800.

38. Abdel-Wahab O, Manshouri T, Patel J, Harris K, Yao J, Hedvat C, Heguy A, Bueso-Ramos C, Kantarjian H, Levine RL, Verstovsek S: Genetic analysis of transforming events that convert chronic myeloproliferative neoplasms to leukemias. Cancer Res 2010, 70:447-452

39. Chou WC, Huang HH, Hou HA, Chen CY, Tang JL, Yao M, Tsay W, Ko BS, Wu SJ, Huang SY, et al: Distinct clinical and biological features of de novo acute myeloid leukemia with additional sex comb-like 1 (ASXL1) mutations. Blood 2010, 116:4086-4094.

40. Owen C, Fitzgibbon J, Paschka P: The clinical relevance of Wilms Tumour 1 (WT1) gene mutations in acute leukaemia. Hematol Oncol 2010, 28:13-19.

41. Paschka P, Marcucci G, Ruppert AS, Whitman SP, Mrozek K, Maharry K, Langer C, Baldus CD, Zhao W, Powell BL, et al: Wilms' tumor 1 gene mutations independently predict poor outcome in adults with cytogenetically normal acute myeloid leukemia: a cancer and leukemia group B study. J Clin Oncol 2008, 26:4595-4602.

42. Hou HA, Huang TC, Lin LI, Liu CY, Chen CY, Chou WC, Tang JL, Tseng MH, Huang CF, Chiang YC, et al: WT1 mutation in 470 adult patients with acute myeloid leukemia: stability during disease evolution and implication of its incorporation into a survival scoring system. Blood 2010, 115:5222-5231

43. Becker H, Marcucci G, Maharry K, Radmacher MD, Mrozek K, Margeson D, Whitman SP, Paschka P, Holland KB, Schwind S, et al: Mutations of the Wilms tumor 1 gene (WT1) in older patients with primary cytogenetically normal acute myeloid leukemia: a Cancer and Leukemia Group B study. Blood 2010, 116:788-792.

44. Nakao M, Yokota S, Iwai T, Kaneko H, Horiike S, Kashima K, Sonoda Y, Fujimoto T, Misawa S: Internal tandem duplication of the flt3 gene found in acute myeloid leukemia. Leukemia 1996, 10:1911-1918.

45. Yamamoto Y, Kiyoi H, Nakano Y, Suzuki R, Kodera Y, Miyawaki S, Asou N, Kuriyama K, Yagasaki F, Shimazaki C, et al: Activating mutation of D835 within the activation loop of FLT3 in human hematologic malignancies. Blood 2001, 97:2434-2439.

46. Bacher U, Haferlach C, Kern W, Haferlach T, Schnittger S: Prognostic relevance of FLT3-TKD mutations in AML: the combination matters-an analysis of 3082 patients. Blood 2008, 111:2527-2537.

47. Yokota S, Kiyoi H, Nakao M, Iwai T, Misawa S, Okuda T, Sonoda Y, Abe T, Kahsima K, Matsuo Y, Naoe T: Internal tandem duplication of the FLT3 gene is preferentially seen in acute myeloid leukemia and myelodysplastic syndrome among various hematological malignancies. A study on a large series of patients and cell lines. Leukemia 1997, 11:1605-1609.

48. Schnittger S, Schoch C, Dugas M, Kern W, Staib P, Wuchter C, Loffler H, Sauerland CM, Serve $H$, Buchner T, et al: Analysis of FLT3 length mutations in 1003 patients with acute myeloid leukemia: correlation to cytogenetics, FAB subtype, and prognosis in the AMLCG study and usefulness as a marker for the detection of minimal residual disease. Blood 2002, 100:59-66.

49. Kottaridis PD, Gale RE, Frew ME, Harrison G, Langabeer SE, Belton AA, Walker H, Wheatley $\mathrm{K}$, Bowen DT, Burnett AK, et al: The presence of a FLT3 internal tandem duplication in patients with acute myeloid leukemia (AML) adds important prognostic information to cytogenetic risk group and response to the first cycle of chemotherapy: analysis of 854 patients from the United Kingdom Medical Research Council AML 10 and 12 trials. Blood 2001, 98:1752-1759.

50. Meshinchi S, Woods WG, Stirewalt DL, Sweetser DA, Buckley JD, Tjoa TK, Bernstein ID, Radich JP: Prevalence and prognostic significance of Flt3 internal tandem duplication in pediatric acute myeloid leukemia. Blood 2001, 97:89-94.

51. Kiyoi H, Naoe T, Nakano Y, Yokota S, Minami S, Miyawaki S, Asou N, Kuriyama K, Jinnai I, Shimazaki C, et al: Prognostic implication of FLT3 and N-RAS gene mutations in acute myeloid leukemia. Blood 1999, 93:3074-3080.

52. Frohling S, Schlenk RF, Breitruck J, Benner A, Kreitmeier S, Tobis K, Dohner H, Dohner K: Prognostic significance of activating FLT3 mutations in younger adults (16 to 60 years) with acute myeloid leukemia and normal cytogenetics: a study of the AML Study Group Ulm. Blood 2002, 100:4372-4380.

53. Ozeki K, Kiyoi H, Hirose Y, Iwai M, Ninomiya M, Kodera Y, Miyawaki S, Kuriyama $\mathrm{K}$, Shimazaki $\mathrm{C}$, Akiyama $\mathrm{H}$, et al: Biologic and clinical significance of the FLT3 transcript level in acute myeloid leukemia. Blood 2004, 103:1901-1908.

54. Kuchenbauer F, Kern W, Schoch C, Kohlmann A, Hiddemann W, Haferlach T, Schnittger S: Detailed analysis of FLT3 expression levels in acute myeloid leukemia. Haematologica 2005, 90:1617-1625.

55. Thiede C, Steudel C, Mohr B, Schaich M, Schakel U, Platzbecker U, Wermke M, Bornhauser M, Ritter M, Neubauer A, et al: Analysis of FLT3activating mutations in 979 patients with acute myelogenous leukemia: association with $\mathrm{FAB}$ subtypes and identification of subgroups with poor prognosis. Blood 2002, 99:4326-4335.

56. Noguera NI, Breccia M, Divona M, Diverio D, Costa V, De Santis S, Avvisati G, Pinazzi MB, Petti MC, Mandelli F, Lo Coco F: Alterations of the FLT3 gene in acute promyelocytic leukemia: association with diagnostic characteristics and analysis of clinical outcome in patients treated with the Italian AIDA protocol. Leukemia 2002, 16:2185-2189. 
57. Beitinjaneh A, Jang S, Roukoz H, Majhail NS: Prognostic significance of FLT3 internal tandem duplication and tyrosine kinase domain mutations in acute promyelocytic leukemia: a systematic review. Leuk Res 2010, 34:831-836.

58. Oyarzo MP, Lin $P$, Glassman A, Bueso-Ramos CE, Luthra R, Medeiros LJ: Acute myeloid leukemia with $\mathrm{t}(6 ; 9)(\mathrm{p} 23 ; \mathrm{q} 34)$ is associated with dysplasia and a high frequency of flt3 gene mutations. Am J Clin Pathol 2004, 122:348-358

59. Steudel C, Wermke M, Schaich M, Schakel U, Illmer T, Ehninger G, Thiede C: Comparative analysis of MLL partial tandem duplication and FLT3 internal tandem duplication mutations in 956 adult patients with acute myeloid leukemia. Genes Chromosomes Cancer 2003, 37:237-251.

60. Carnicer MJ, Nomdedeu JF, Lasa A, Estivill C, Brunet S, Aventin A, Sierra J: FLT3 mutations are associated with other molecular lesions in AML. Leuk Res 2004, 28:19-23.

61. Matozaki T, Murata Y, Saito Y, Okazawa H, Ohnishi H: Protein tyrosine phosphatase SHP-2: a proto-oncogene product that promotes Ras activation. Cancer Sci 2009, 100:1786-1793.

62. Hou HA, Chou WC, Lin LI, Chen CY, Tang JL, Tseng MH, Huang CF, Chiou RJ, Lee FY, Liu MC, Tien HF: Characterization of acute myeloid leukemia with PTPN11 mutation: the mutation is closely associated with NPM1 mutation but inversely related to FLT3/ITD. Leukemia 2008, 22:1075-1078.

63. Renneville A, Roumier C, Biggio V, Nibourel O, Boissel N, Fenaux P, Preudhomme C: Cooperating gene mutations in acute myeloid leukemia: a review of the literature. Leukemia 2008, 22:915-931.

64. Bacher U, Haferlach T, Schoch C, Kern W, Schnittger S: Implications of NRAS mutations in AML: a study of 2502 patients. Blood 2006, 107:3847-3853.

65. Cairoli R, Beghini A, Grillo G, Nadali G, Elice F, Ripamonti CB, Colapietro P, Nichelatti M, Pezzetti L, Lunghi M, et al: Prognostic impact of c-KIT mutations in core binding factor leukemias: an Italian retrospective study. Blood 2006, 107:3463-3468

66. Schnittger S, Kohl TM, Haferlach T, Kern W, Hiddemann W, Spiekermann K, Schoch C: KIT-D816 mutations in AML1-ETO-positive AML are associated with impaired event-free and overall survival. Blood 2006, 107:1791-1799.

67. Wang $Y Y$, Zhou GB, Yin T, Chen B, Shi JY, Liang WX, Jin XL, You JH, Yang G, Shen ZX, et al: AML1-ETO and C-KIT mutation/overexpression in t(8;21) leukemia: implication in stepwise leukemogenesis and response to Gleevec. Proc Natl Acad Sci USA 2005, 102:1104-1109.

68. Paschka P, Marcucci G, Ruppert AS, Mrozek K, Chen H, Kittles RA, Vukosavljevic T, Perrotti D, Vardiman JW, Carroll AJ, et al: Adverse prognostic significance of KIT mutations in adult acute myeloid leukemia with inv(16) and t(8;21): a Cancer and Leukemia Group B Study. J Clin Oncol 2006, 24:3904-3911.

69. Kuchenbauer F, Schnittger S, Look T, Gilliland G, Tenen D, Haferlach T, Hiddemann W, Buske C, Schoch C: Identification of additional cytogenetic and molecular genetic abnormalities in acute myeloid leukaemia with $\mathrm{t}$ (8;21)/AML1-ETO. Br J Haematol 2006, 134:616-619.

70. Bacher U, Haferlach C, Schnittger S, Kohlmann A, Kern W, Haferlach T: Mutations of the TET2 and CBL genes: novel molecular markers in myeloid malignancies. Ann Hematol 2010, 89:643-652.

71. Sargin B, Choudhary C, Crosetto N, Schmidt MH, Grundler R, Rensinghoff M, Thiessen C, Tickenbrock L, Schwable J, Brandts C, et al: Flt3-dependent transformation by inactivating c-Cbl mutations in AML. Blood 2007, 110:1004-1012.

72. Reindl C, Quentmeier H, Petropoulos K, Greif PA, Benthaus T, Argiropoulos B, Mellert G, Vempati S, Duyster J, Buske C, et al: CBL exon 8/ 9 mutants activate the FLT3 pathway and cluster in core binding factor/ $11 \mathrm{q}$ deletion acute myeloid leukemia/myelodysplastic syndrome subtypes. Clin Cancer Res 2009, 15:2238-2247.

73. Haferlach C, Dicker F, Kohlmann A, Schindela S, Weiss T, Kern W, Schnittger S, Haferlach T: AML with CBFB-MYH11 rearrangement demonstrate RAS pathway alterations in $92 \%$ of all cases including a high frequency of NF1 deletions. Leukemia 2010, 24:1065-1069.

74. Ito Y: Oncogenic potential of the RUNX gene family: 'overview'. Oncogene 2004, 23:4198-4208

75. Gaidzik VI, Bullinger L, Schlenk RF, Zimmermann AS, Rock J, Paschka P Corbacioglu A, Krauter J, Schlegelberger B, Ganser A, et al: RUNX mutations in acute myeloid leukemia: results from a comprehensive genetic and clinical analysis from the AML study group. J Clin Oncol 2011, 29:1364-1372.

76. Tang JL, Hou HA, Chen CY, Liu CY, Chou WC, Tseng MH, Huang CF, Lee FY, Liu MC, Yao M, et al: AML1/RUNX1 mutations in 470 adult patients with de novo acute myeloid leukemia: prognostic implication and interaction with other gene alterations. Blood 2009, 114:5352-5361.

77. Schnittger S, Dicker F, Kern W, Wendland N, Sundermann J, Alpermann T, Haferlach C, Haferlach T: RUNX1 mutations are frequent in de novo AML with noncomplex karyotype and confer an unfavorable prognosis. Blood 2011, 117:2348-2357.

78. Pabst T, Mueller BU, Zhang P, Radomska HS, Narravula S, Schnittger S, Behre G, Hiddemann W, Tenen DG: Dominant-negative mutations of CEBPA, encoding CCAAT/enhancer binding protein-alpha (C/EBPalpha), in acute myeloid leukemia. Nat Genet 2001, 27:263-270.

79. Pabst T, Mueller BU: Transcriptional dysregulation during myeloid transformation in AML. Oncogene 2007, 26:6829-6837.

80. Marcucci G, Maharry K, Radmacher MD, Mrozek K, Vukosavljevic T, Paschka P, Whitman SP, Langer C, Baldus CD, Liu CG, et al: Prognostic significance of, and gene and microRNA expression signatures associated with, CEBPA mutations in cytogenetically normal acute myeloid leukemia with high-risk molecular features: a Cancer and Leukemia Group B Study. J Clin Oncol 2008, 26:5078-5087.

81. Basecke J, Whelan JT, Griesinger F, Bertrand FE: The MLL partial tandem duplication in acute myeloid leukaemia. Br J Haematol 2006, 135:438-449.

82. Yu BD, Hess JL, Horning SE, Brown GA, Korsmeyer SJ: Altered Hox expression and segmental identity in Mll-mutant mice. Nature 1995, 378:505-508.

83. Milne TA, Briggs SD, Brock HW, Martin ME, Gibbs D, Allis CD, Hess JL: MLL targets SET domain methyltransferase activity to Hox gene promoters. Mol Cell 2002, 10:1107-1117.

84. Munoz L, Nomdedeu JF, Villamor N, Guardia R, Colomer D, Ribera JM, Torres JP, Berlanga JJ, Fernandez C, Llorente A, et al: Acute myeloid leukemia with MLL rearrangements: clinicobiological features, prognostic impact and value of flow cytometry in the detection of residual leukemic cells. Leukemia 2003, 17:76-82

85. Reilly JT: Pathogenesis of acute myeloid leukaemia and inv(16)(p13;q22): a paradigm for understanding leukaemogenesis? Br J Haematol 2005, 128:18-34.

86. Gregory TK, Wald D, Chen Y, Vermaat JM, Xiong Y, Tse W: Molecular prognostic markers for acute myeloid leukemia with normal cytogenetics. J Hematol Oncol 2009, 2:23.

87. Zhu X, Ma Y, Liu D: Novel agents and regimens for acute myloid leukemia: 2009 ASH annual meeting highlights. J Hematol Oncol 2010 $3: 17$.

doi:10.1186/1756-8722-4-36

Cite this article as: Takahashi: Current findings for recurring mutations

in acute myeloid leukemia. Journal of Hematology \& Oncology 2011 4:36.

\section{Submit your next manuscript to BioMed Central and take full advantage of:}

- Convenient online submission

- Thorough peer review

- No space constraints or color figure charges

- Immediate publication on acceptance

- Inclusion in PubMed, CAS, Scopus and Google Scholar

- Research which is freely available for redistribution

Submit your manuscript at www biomedcentral com/submit
C Biomed Central 